\title{
Enlargement of Useful Lifespan of Different Garments by Adopting Refashion
}

\author{
Md. Suruj-Zaman', Khurshid Jahan', Farhana Sharmin Nisa1, Raihan Hossain1, Al Amin Ador', \\ Md. Sabbir Hossain1, Md. Nazmul Hasan Khandoker ${ }^{1,2}$, Taosif Ahmed 1,3* (1)
}

${ }^{1}$ Department of Textile Engineering, National Institute of Textile Engineering \& Research (NITER), Savar, Dhaka, Bangladesh
${ }^{2}$ School of Fashion, Wuhan Textile University, Wuhan, China
${ }^{3}$ School of Environmental Engineering, Wuhan Textile University, Wuhan, China

Email: *taosif.ahmed@outlook.com

How to cite this paper: Suruj-Zaman, Md. Jahan, K., Nisa, F. S., Hossain, R., Ador, A. A., Hossain, Md. S., Khandoker, Md. N. H., \& Ahmed, T. (2021). Enlargement of Useful Lifespan of Different Garments by Adopting Refashion. Art and Design Review, 9, 1-18.

https://doi.org/10.4236/adr.2021.91001

Received: November 18, 2020

Accepted: December 27, 2020

Published: December 30, 2020

Copyright (c) 2021 by author(s) and Scientific Research Publishing Inc. This work is licensed under the Creative Commons Attribution International License (CC BY 4.0).

http://creativecommons.org/licenses/by/4.0/

\begin{abstract}
In this research work, the lifetime of different garments has been investigated by surveying 500 people. Also, the lifetime of the same items has been investigated by following the same procedure after adopting refashion. The difference in life before and after refashion has been investigated as well. The survey result shows that the lifetime of the garments items increases to a greater extent after adopting refashion. As it is possible to increase the lifetime of garments by refashioning so the refashion technique followed in this research work has an environmental, social, and economic impact to obtain enrich and greener world.
\end{abstract}

\section{Keywords}

Refashion, Redesign, Clothing, Lifespan, Lifetimes, Sustainable Fashion, Functional Unit

\section{Introduction}

People are becoming fashion conscious and they are purchasing more and more garments. If their demand for garments is fulfilled then the environment will be in danger. The Fashion Industry epitomizes unsustainability with its fast-changing trends, high minimums, and planned obsolescence. Modern patterns of consumerism coincide with an increase in "throwaway" fashion, contributing millions of tons of clothing to landfills, incineration, and third world dumping. The context for this practice-based research is positioned at the interface between the fashion business model of overproduction and over-consumption in clothing manufacture in the developed world. 
Nowadays fast fashion brands produce about 52 "micro seasons" a year (Hischier, 2018). This means at least one new collection every week. According to author Elizabeth Cline, the ever-popular Zara started the craze by shifting to buy weekly deliveries of new merchandise back in the early aught. From then on, it has become the norm to have a towering supply of stock at all times. This model has kept business Next, Charlotte Russe, and Wet Seal from having to encounter running out of a certain style and isolating different customers (Follows \& Jobber, 2000).

All of the elements of fast fashion, trend replication, rapid production, low quality, and competitive pricing, add up to a large impact on the environment and the people involved in its population. The environmental damage, which the fashion industry continues to create, is in large part due to fast fashion Brands like Forever 21 use toxic chemicals, dangerous dyes, and synthetic fabrics which seep into water supplies in foreign countries (where the clothing is made) and at home when the clothing is washed.

Each year, the clothing that is simply thrown away amounts to about 11 million tons in the US alone (Dissanayake \& Sinha, 2015; Shim, 1995). These garments, full of lead, pesticides, and countless other chemicals, almost never break down and spend their life releasing these toxic chemicals in the air. Fast fashion's carbon footprint is giving huge industries like air travel and oil a "run for their money" (Choi, 2013).

Along with the effects fast fashion has on our earth, these processes affect the human who wears them, and the humans who make them. Some garments and accessories even have dangerous amounts of lead in them, and exposure to lead increases one's risk of infertility, heart attacks, and more. Skin is the largest organ of the body and putting on these poorly made items on it is dangerous all on its own. This danger only grows in the factories, towns, and homes which are used to produce these items. A garment worker's health is constantly being jeopardized through their long hours, lack of resources, exposure to harmful chemicals, and often physical abuse. The people who make fast fashion clothing have been confirmed to be underpaid, underfed, and pushed to their limits because there are often few other options (Klepp, Laitala, \& Wiedemann, 2020; Zamani, Sandin \& Peters, 2017).

\section{Research Questions, Objectives}

The main research question of this study is "How much effectively and efficiently increase the useable lifetime of different garments by applying to refashion?” So, in terms of research questions the primary objective is:

- To enlarge the lifespan of different garments.

- To produce re-fashioned and contemporary fashion.

- To ascertain the potential of the Refashion concept to be adapted to fashion business models.

- To inspire new approaches in fashion design and garments production. 


\section{Literature Review}

The drop in garment prices over the last 20 years has allowed us to buy more and more clothes. We now have 5 times more clothes than our grandparents had (Allwood, Laursen, Russell, de Rodriguez, \& Bocken, 2008). It felt great until we found out what was hiding behind this trend. In reality, this continuous accumulation of cheap garments is only possible because of a constant reduction in production costs. This, in turn, has serious consequences on our health, our planet, and garment workers' lives (Ahmed, Mia, \& Tanjim, 2020).

Clothing and textile recycling are the methods of reusing or repurposing used clothing or textiles instead of throwing them in landfills. Textile recycling has the potential to make an enormous environmental and economic impact (Mia, Selim, Shamim, Chowdhury, \& Sultana, 2019; Weber, Lynes, \& Young, 2017). Besides the positive environmental impact, textile recycling is part of the emerging green tech economy that promises to be a wonderful economic energizer. Industry experts estimate that for every 1000 tons of waste diverted from landfill, 7 full time and 15 indirect jobs are created (Reza, Soltani, Ruparathna, Sadiq, \& Hewage, 2013). Used clothing donation bins also save municipalities money in dumping fees annually as well as generate income through licenses and tickets. OWMA \& Recycling Council of Ontario is doing wonderful research on the positive economic potential of waste diversion (Yeheyis, Hewage, Alam, Eskicioglu, \& Sadiq, 2013).

\subsection{Fashion's Environmental Impact}

The fashion industry has a disastrous impact on the environment. It is the second-largest polluter in the world, just after the oil industry (Kozlowski, Bardecki, \& Searcy, 2012). And the environmental damage is increasing as the industry grows. However, there are solutions and alternatives to mitigate these problems. The first step lies in building awareness and willingness to change some fashions environmental impacts are described below.

\subsubsection{Fashion \& Water Pollution}

In most of the countries in which garments are produced, untreated toxic wastewaters from textiles factories are dumped directly into the rivers. Wastewater contains toxic substances such as lead, mercury, and arsenic, among others (Baidya, Ahmed, Mia, Habib-A-Rasul, Das, Bardhan, \& Saha, 2020; Habib-A-Rasul \& Saleh, 2020). These are extremely harmful to the aquatic life and the health of the million people living by those rivers' banks. The contamination also reaches the sea and eventually spreads around the globe. Another major source of water contamination is the use of fertilizers for cotton production, which heavily pollutes runoff waters and evaporation waters.

\subsubsection{Fashion \& Water Consumption}

The fashion industry is a major water consumer. A huge quantity of freshwater is used for the dyeing and finishing process for all of our clothes. As a reference, 
it can take up to 200 tons of freshwater per ton of dyed fabric (Hossain, Sarker, \& Khan, 2018). Also, cotton needs a lot of water to grow (and heat) but is usually cultivated in warm and dry areas. Up to 20,000 liters of water are needed to produce just $1 \mathrm{~kg}$ of cotton (Brenot, Chuffart, Coste-Manière, Deroche, Godat, Lemoine, \& Tornaire, 2019; Fjerbaek, Christensen, \& Norddahl, 2009). This generates tremendous pressure on this precious resource, already scarce, and has dramatic ecological consequences such as the desertification of the Aral Sea, where cotton production has entirely drained the water.

\subsubsection{Fashion \& Waste Accumulation}

Clothing has become disposable. As a result, we generate more and more textile waste. A family in the western world throws away an average of $30 \mathrm{~kg}$ of clothing each year. Only $15 \%$ is recycled or donated, and the rest goes directly to the landfill or is incinerated. Synthetic fibers, such as polyester, are plastic fibers, therefore non-biodegradable and can take up to 200 years to decompose (Mohanty, Misra, \& Hinrichsen, 2000; Tue, Sudaryanto, Minh, Isobe, Takahashi, Viet, \& Tanabe, 2010). Synthetic fibers are used in $72 \%$ of our clothing.

\subsubsection{Fashion \& Chemicals}

Chemicals are one of the main components of our clothes. They are used during fiber production, dyeing, bleaching, and wet processing of each of our garments (Rahman, Haque, Sourav, Rahman, Yesmin, Mia \& Begum, 2020). The heavy use of chemicals in cotton farming is causing diseases and premature death among cotton farmers, along with massive freshwater and ocean water pollution and soil degradation.

\subsubsection{Fashion \& Greenhouse Gas Emissions}

The global fashion industry is generating a lot of greenhouse gases due to the energy used during its production, manufacturing, and transportation of the millions of garments purchased each year (Koszewska, 2018; O'Cass, 2004). Synthetic fibers (polyester, acrylic, nylon, etc.), used in the majority of our clothes, are made from fossil fuel, making production much more energy-intensive than with natural fibers. Most of our clothes are produced in China, Bangladesh, or India, countries essentially powered by coal. This is the dirtiest type of energy in terms of carbon emissions.

\subsubsection{Fashion \& Rainforest Destruction}

Every year, thousands of hectares of endangered and ancient forests are cut down and replaced by plantations of trees used to make wood-based fabrics such as rayon, viscose, and modal (Brink \& Escobin, 2003; Gwilt \& Rissanen, 2012). This and indigenous communities, as in Indonesia where large-scale deforestation of the rainforests has taken place over the past decade.

\section{Research Design \& Methodology}

We have collected our required raw materials (Denim jacket, T-shirt, woven 
shirt, etc.). Then find a useful lifetime of the garments items before refashioning by conducting a survey. After that, converting the old garments items by adopting refashion ideas. Again, find a useful lifetime of the garments items after refashioning by conducting the survey. Finally, investigation of the difference of lifetime of the garments items before and after refashion as well as environmental, social, and economic impact (Figure 1).

\subsection{Materials}

- Denim jacket

- Lace

- Knit T-shirt

- Denim pants

- Woven shirt

- Knit trouser

- Jersey

- Sewing thread

- Button

- Ribbon

- Fabric gum

\subsection{Machines/Equipment}

- Lock stitch machine

- Over lock machine

- Scissor

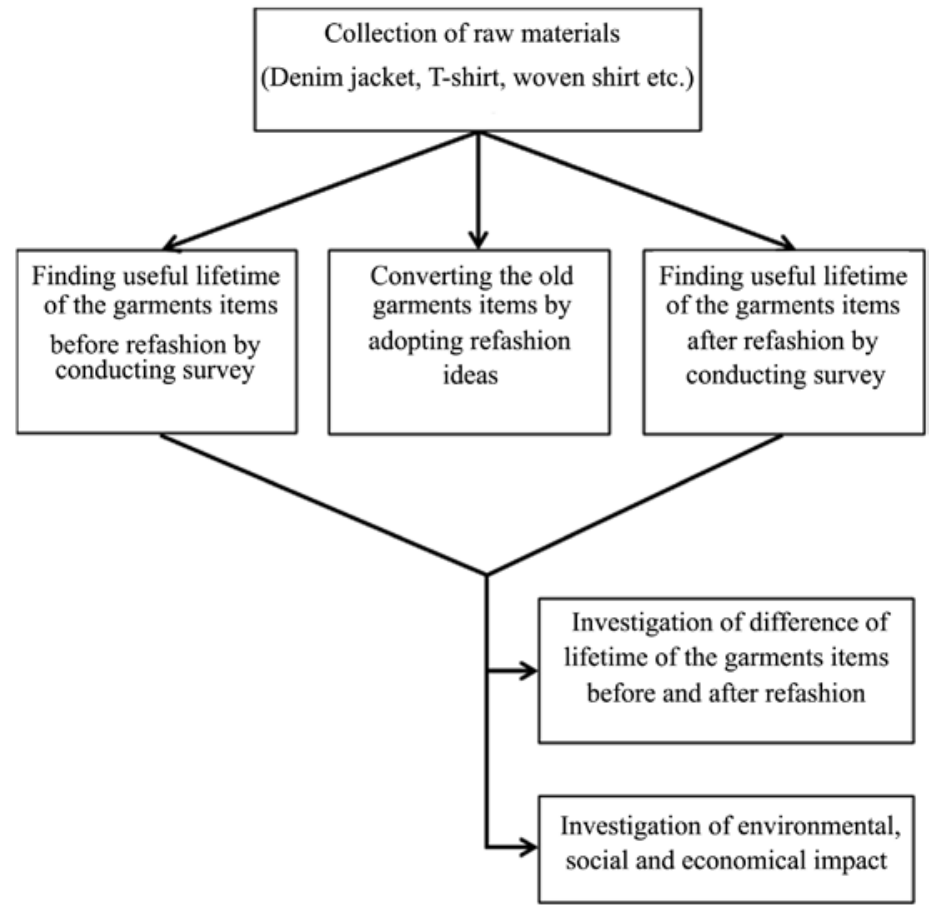

Figure 1. Schematic illustration of research design. 
- Measuring tape

- Chalk

\subsection{Method}

\section{Refashion approach 1: (Converting denim jacket into fashionable top)}

Took a very heavy denim jacket and cut the sleeve and back part of the jacket. Then attach the white lace to that part so that the weight of the jacket was reduced and look like a fashionable jacket.

Refashion approach 2: ( $\mathrm{T}$-shirt converted into woven structured stylish T-shirt)

We took 2 used t-shirt (Black and white) and cut the white t-shirt along the seam line and cut it into a small rectangular shape. Then fold the small pieces and sew them on the open edges. Then, we have made rope with every piece of small rectangular cloth pieces. Again, we took the black t-shirt and cut it in the chest section with a defined measurement like the picture. They were like warp of weaving structure. Interlaced the small pieces of white with black and made the weaving structure. Then, sew four sides of the structure for reinforcement. Finally, we got our refashioned weaved structure t-shirt.

\section{Refashion approach 3: (Jeans converted into jacket)}

Firstly, we took old men's jeans. Then, take off the back pockets from the jeans. After that, we folded the pants in half and drew a line from the bottom of the jeans for making the sleeve of the jacket. Then, cut the pocket fabric attached to the pieces and folded the body parts along the stitched seam line. Then we took the sleeve parts and place them on top of each other and cut the sleeves from these parts. After that, we attached the sleeves to the main body of the jacket and stitched the seams, and close the sleeves. Then, we cut the front boy part for making an opening and attached the pockets to the front parts. Again, we attached the waistband to the collar of the jacket and Hem the edges of the front parts. That's how we made our full sleeve jacket from old jeans.

\section{Refashion approach 4: (Basic shirt converted into baby frock)}

Firstly, we took an old man's shirt. Then we lay the shirt on a flat table and cut the armhole and neck portion. Then fold it from the center position and point out the measurement of a baby's armhole and shoulder size with chalk. Then cut the armhole and neck according to the measurement. Then we joined the shoulder with a lockstitch machine and stitched the armhole neck with elastic so that it looks fit. Also, we attached the ribbon on the waistline to look fashionable.

Refashion approach 5: (Ladies T-shirt converted into more stylish look)

Firstly, we took a plain T-shirt and took some colorful buttons and attached them with the help of fabric glue on the front side of the t-shirt according to the design. Then took a colorful lace and sew it around the waist of the t-shirt. After that, we got a refashioned stylish t-shirt.

Refashion approach 6: (Ladies shirt converted into ladies' top)

Took an old woven shirt and then lay the shirt on a flat table and cut the neck, 
cuff, and bottom edge. Then fold it from the center position and point out the measurement of the neck with chalk. After that, cut the neck according to the measurement and stitch the neck and sleeve with elastic so that it looks fit. Also, attach the lace on the left front side to look fashionable.

\section{Refashion approach 7: (Laggings converted into crop-top)}

We took a knitted pink trouser and took a scissor and cut in the crotch point of the trouser according to the measurement of the neck. Then cut off the leg opening and make strands by cutting the leg panel. Make some braids from the strands and took some colorful dollars and attach them with the help of fabric glue on the front side. Then we took a black lace and sew it around the neck. After that, we got the refashioned stylish crop top out of trousers.

\section{Refashion approach 8: (Summer T-shirt converted into winter shirt)}

Firstly, we took a long ash-colored t-shirt and a denim jacket. Then cut the sleeves of the denim jacket and attach them with the sleeves of the $t$-shirt. After that, cut the back part of the denim jacket according to a suitable shape and sew it in the front side of the t-shirt as a pocket and then took two buttons and attached them to the pocket.

\section{Refashion approach 9: ( $\mathrm{T}$-shirt converted into casual jacket)}

We took a round neck half sleeve $t$-shirt and cut the seam line and upper and lower folded line of the sleeve and only the seam line and lower folded part on the other side. Then lay the t-shirt on any flat space and fold the t-shirt like the picture (Figure 2) so that the body of the t-shirt became the sleeves of the jacket and the sleeves became the body. After that, fold the small pieces and sew them on the open edges and flip them over. Draw a line from the sleeve of the new jacket for tightness or looseness of the sleeves. Stitch along the sleeves and seam. Finally, we made our stylish jacket from an old t-shirt.

\section{Refashion approach 10: (Jeans converted into detachable overall)}

We took an old pair of jeans pants and cut it along the crouch point and made patterns of front and back part. Then, cut the straps with the pocket parts. After
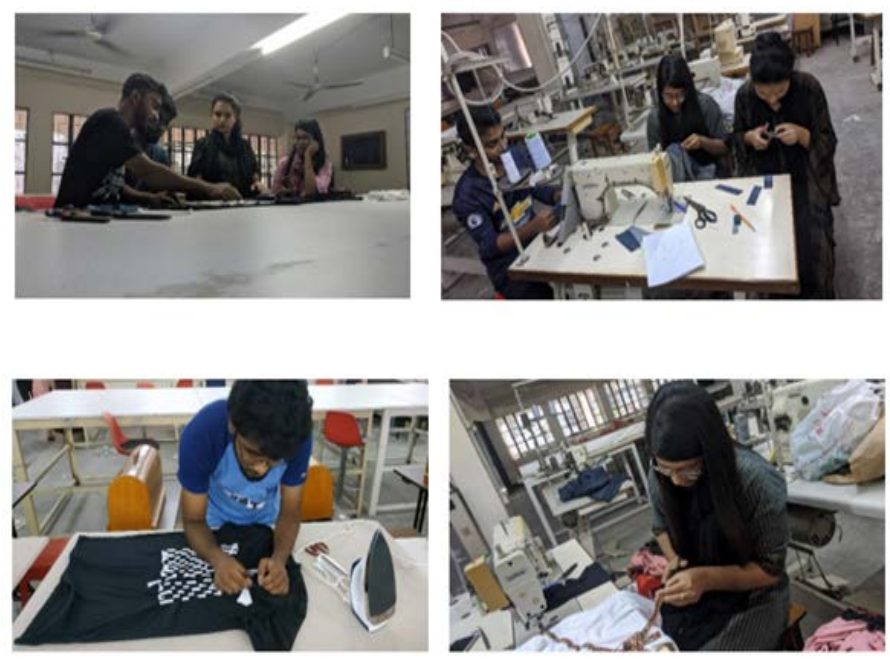

Figure 2. Authors performing refashion of garments. 
that, secure the edges of the front part and back parts by sewing the edges and Join the back parts together and sew the front parts with the back part. Lastly, add the straps to the specific parts and we got our desire product.

\section{Results and Discussion}

\section{Survey Results}

A survey has been performed over 500 youth people age between 20 to 23 years old and the outcome of the survey is satisfactory (Table 1). Before refashion of the garments brought to the participant of the survey to those group of people and they have asked that how many days they will be used that garments and collect data by interviewing them and after the refashioned then again bring the refashioned garments to them to ask them again how many days they will use that garments. Positive results have been provided by the survey participant.

\section{Refashion approach 1: Jacket converted into more stylish form}

The old denim jacket shows more attraction after refashion (Figure 3). As per the survey result, the lifetime of the old denim jacket before refashion is 51 days, and the value increases to 80 days after refashion. Hence it can be concluded that the lifetime of the mentioned item increases to 29 days, it can be concluded that the useful lifespan of the old denim jacket increases to a great extent (Figure 4).

Refashion approach 2: T-shirt converted into woven structured stylish T-shirt
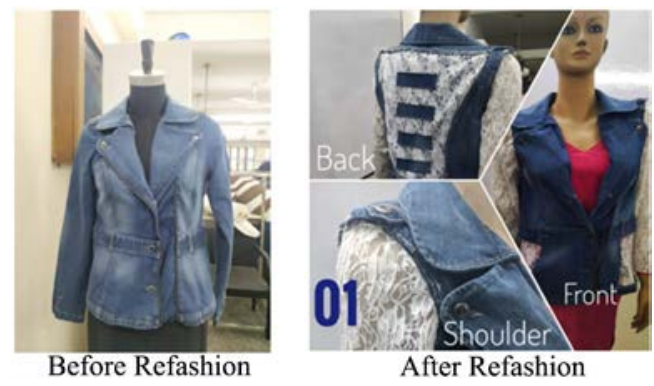

Figure 3. Denim jacket before and after refashion.

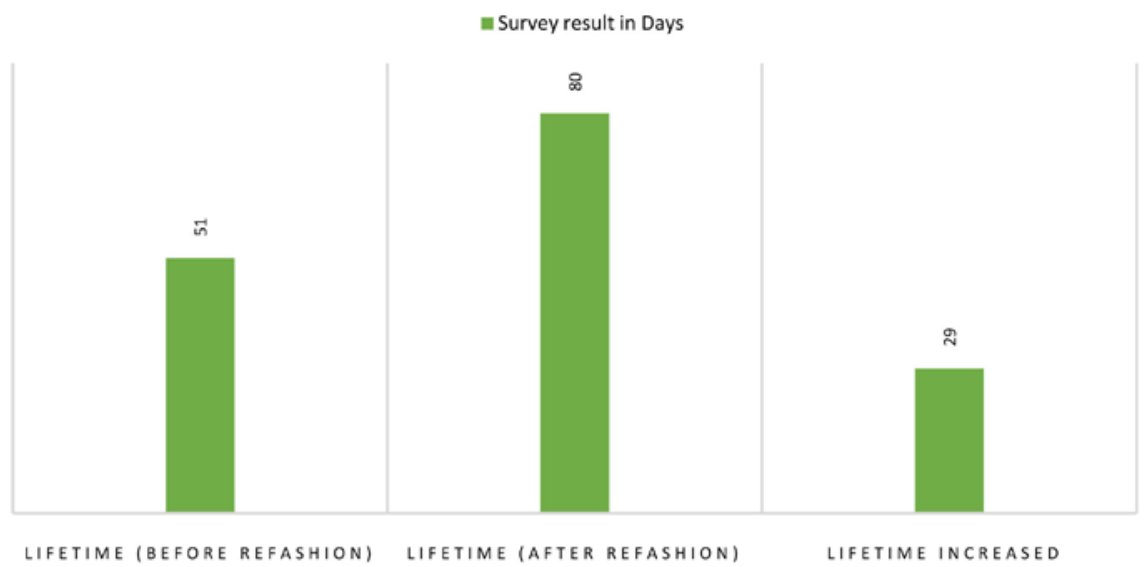

Figure 4. Lifetime (in days) of old denim jacket before refashion and after refashion. 
Table 1. Survey results.

\begin{tabular}{|c|c|c|c|c|}
\hline Sl. & Items & $\begin{array}{c}\text { Lifetime } \\
\text { before } \\
\text { Refashion } \\
\text { (Days) }\end{array}$ & $\begin{array}{c}\text { Lifetime } \\
\text { after } \\
\text { Refashion } \\
\text { (Days) }\end{array}$ & $\begin{array}{c}\text { Lifetime } \\
\text { Increased } \\
\text { (Days) }\end{array}$ \\
\hline 1 & $\begin{array}{l}\text { Refashion approach 1: } \\
\text { Jacket converted into more stylish form }\end{array}$ & 51 & 80 & 29 \\
\hline 2 & $\begin{array}{l}\text { Refashion approach 2: } \\
\text { T-Shirt converted into woven structured stylish T-shirt }\end{array}$ & 31 & 60 & 29 \\
\hline 3 & $\begin{array}{l}\text { Refashion approach 3: } \\
\text { Jeans converted into jacket }\end{array}$ & 47 & 71 & 24 \\
\hline 4 & $\begin{array}{l}\text { Refashion approach 4: } \\
\text { Basic shirt converted into Baby frock }\end{array}$ & 49 & 76 & 27 \\
\hline 5 & $\begin{array}{l}\text { Refashion approach 5: } \\
\text { Ladies T-shirt converted into more stylish look }\end{array}$ & 51 & 88 & 37 \\
\hline 6 & $\begin{array}{l}\text { Refashion approach: } \\
\text { Ladies shirt converted into lady's top }\end{array}$ & 49 & 93 & 44 \\
\hline 7 & $\begin{array}{l}\text { Refashion approach: } \\
\text { Laggings converted into Crop-top }\end{array}$ & 42 & 70 & 28 \\
\hline 8 & $\begin{array}{l}\text { Refashion approach: } \\
\text { Summer T-shirt converted into winter shirt }\end{array}$ & 41 & 65 & 24 \\
\hline 9 & $\begin{array}{l}\text { Refashion approach: } \\
\text { T-shirt converted into Casual jacket }\end{array}$ & 43 & 89 & 46 \\
\hline 10 & $\begin{array}{l}\text { Refashion approach: } \\
\text { Jeans converted into Detachable overall }\end{array}$ & 49 & 82 & 33 \\
\hline
\end{tabular}

Here a simple black T-shirt gets a unique look after it is refashioned (Figure 5). A Survey of 500 people shows that the lifetime of the old t-shirt before refashion is 31 days and the value increases to 60 days after refashion. Hence it can be concluded that the lifetime of the mentioned item increases to 29 days as well as the useful lifespan of the old t-shirt increases in great value (Figure 6).

\section{Refashion approach 3: Jeans converted into jacket}

The old denim pant has been converted into a fashionable denim jacket which catches more attraction of people (Figure 7). From the survey, it can be concluded that the lifetime of the old jeans before refashion is 47 days, and the value increases to 71 days after refashion. Hence the lifetime of the mentioned item increases to 24 days which is a great success (Figure 8).

\section{Refashion approach 4: Basic shirt converted into baby frock}

A beautiful baby frock has been created from an old woven shirt. This refashions work got the most appreciation from the people (Figure 9). from the survey, it can be said that the lifetime of the old woven shirt before refashions is 49 days, and the value increases to 76 days after refashion which shows that lifetime of the mentioned item increases to 27 days. It shows that there is no such thing as waste. People can use the same garment by transforming (Figure 10).

Refashion approach 5: Ladies T-shirt converted into more stylish look

The old $\mathrm{t}$-shirt got a new fashionable look after adding some value to it. This transformation was also a popular one (Figure 11). As per survey result over the 


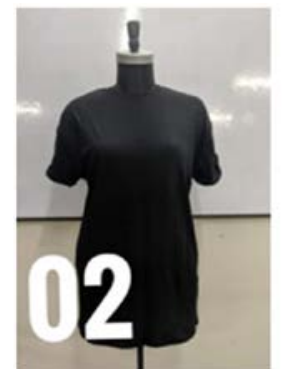

Before Refashion

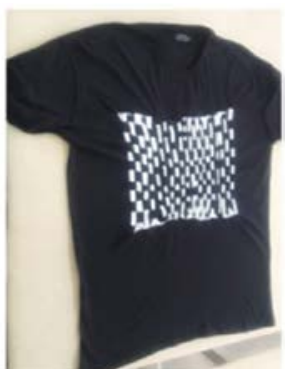

After Refashion

Figure 5. T-shirt before and after refashion.

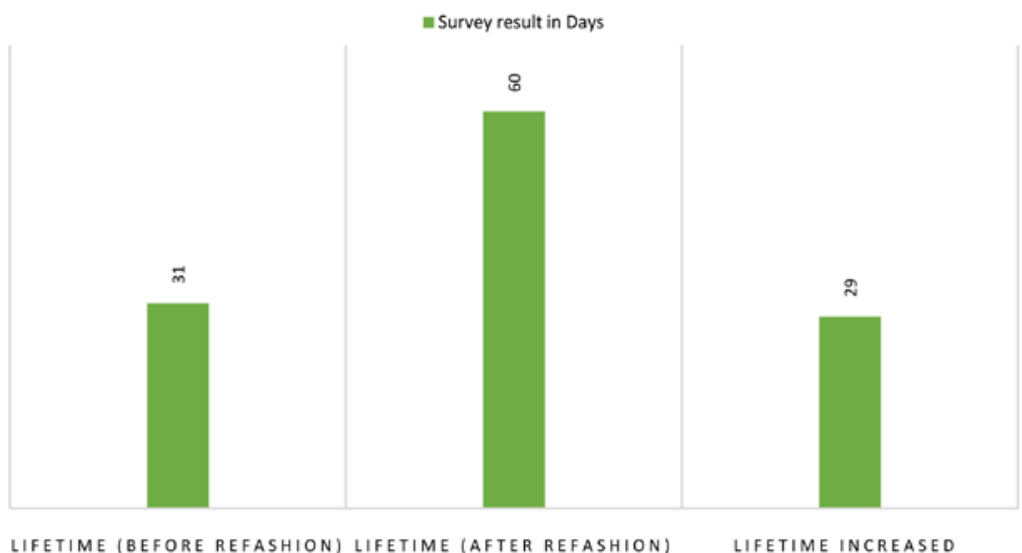

Figure 6. Lifetime (in days) of old T-shirt before refashion and after refashion.
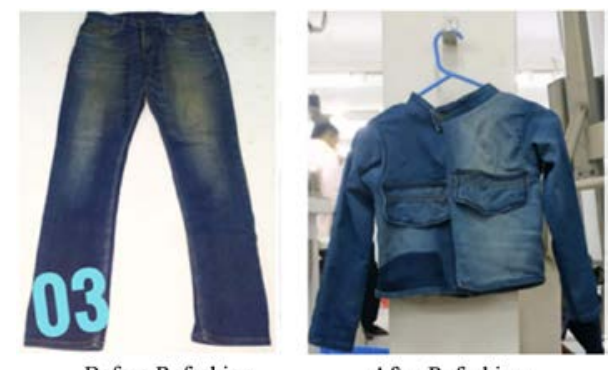

After Refashion

Figure 7. Jeans before and after refashion.

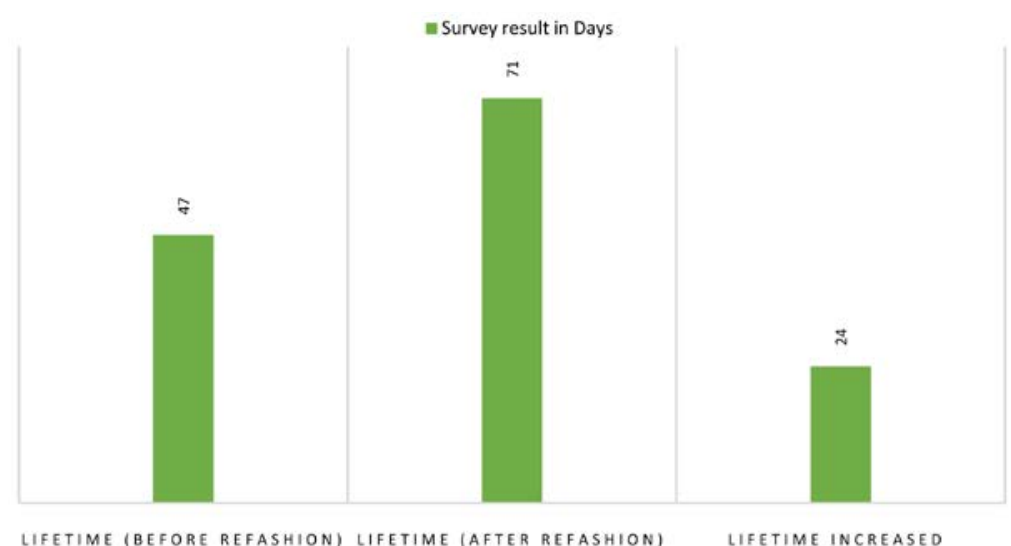

Figure 8. Lifetime (in days) of old denim jeans before refashion and after refashion. 


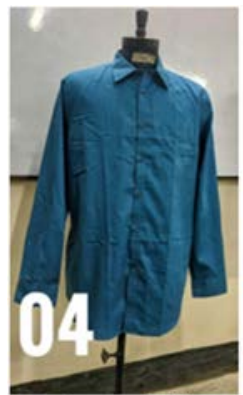

Before Refashion

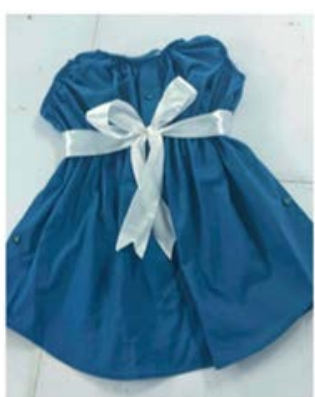

After Refashion

Figure 9. Basic shirt before and after refashion.

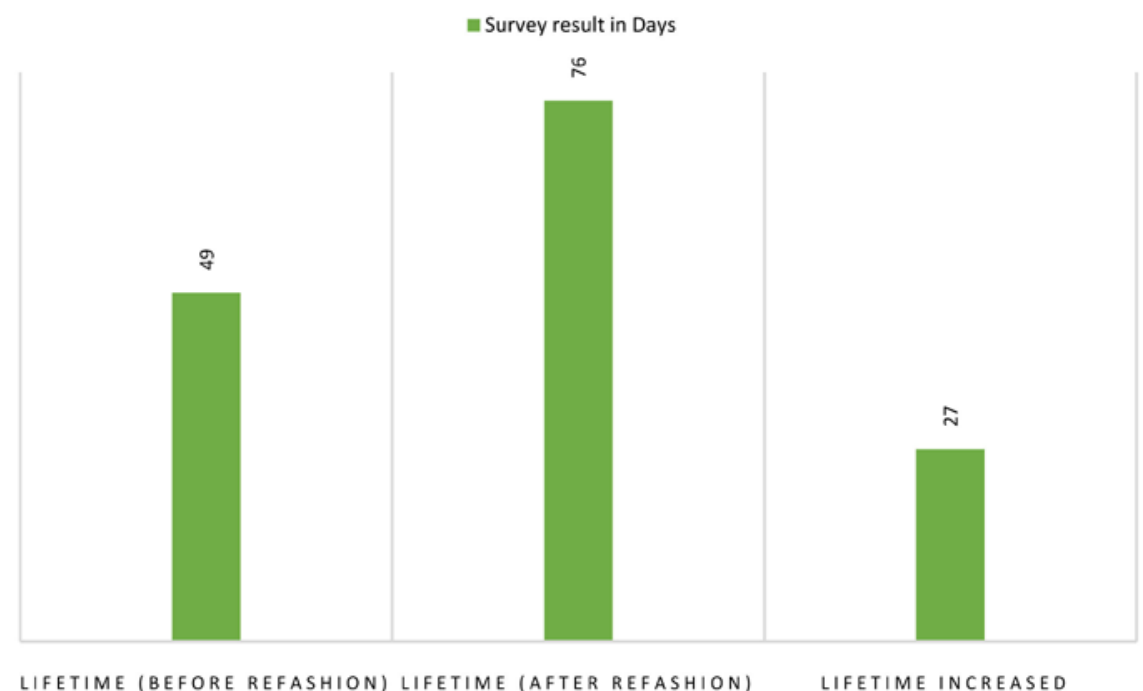

Figure 10. Lifetime (in days) of old woven shirt before refashion and after refashion.
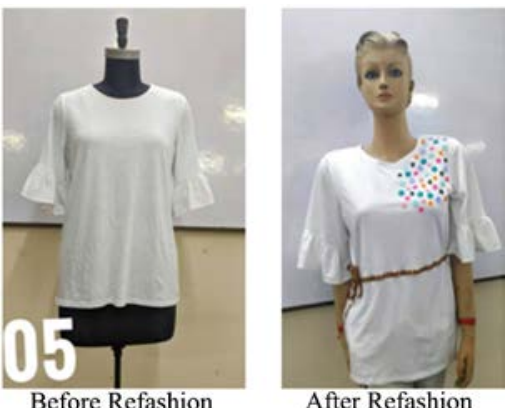

Figure 11. T-shirt before and after refashion.

500 people, the lifetime of the old t-shirt before refashion is 51 days and the value increases to 88 days after refashioning which shows a remarkable increase in the lifetime of 37 days, it can be concluded that people are attracted to the refashioned garments which will reduce waste (Figure 12).

\section{Refashion approach 6: Ladies shirt converted into ladies' top}

A woven shirt can also be transformed into a lady's top by refashioning. Adding a little value can bring a huge change in the overall look of the garment (Figure 13). From survey result over 500 people shows the lifetime of the old 
woven shirt before refashion is 49 days and the value increases to 93 days after refashion. Hence it can be concluded that the lifetime of the mentioned item increases to 44 days, it can be concluded that the useful lifespan of the old woven shirt increases in a great value (Figure 14).

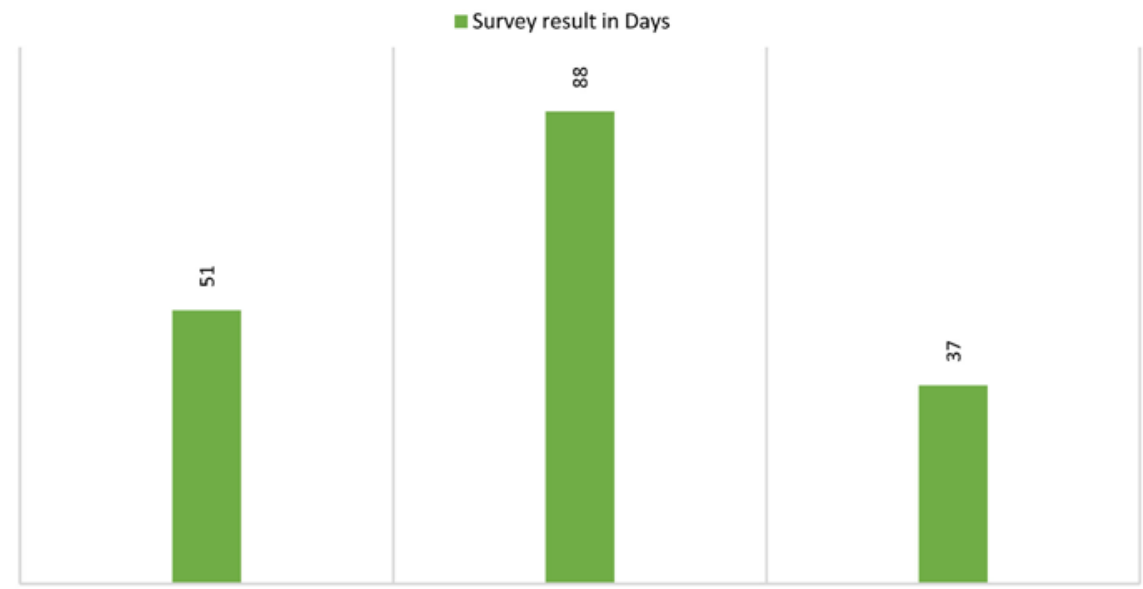

LIFETIME (BEFORE REFASHION) LIFETIME (AFTER REFASHION) LIFETIME INCREASED

Figure 12. Lifetime (in days) of T-shirt before refashion and after refashion.
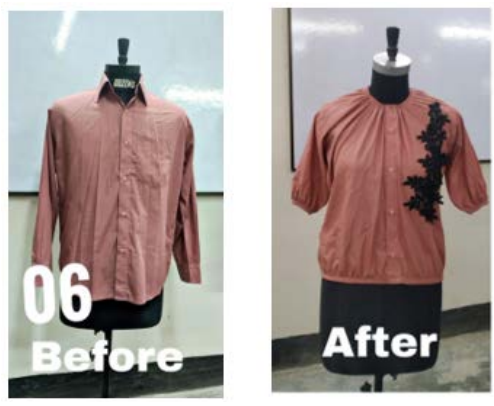

Figure 13. Woven shirt before and after refashion.

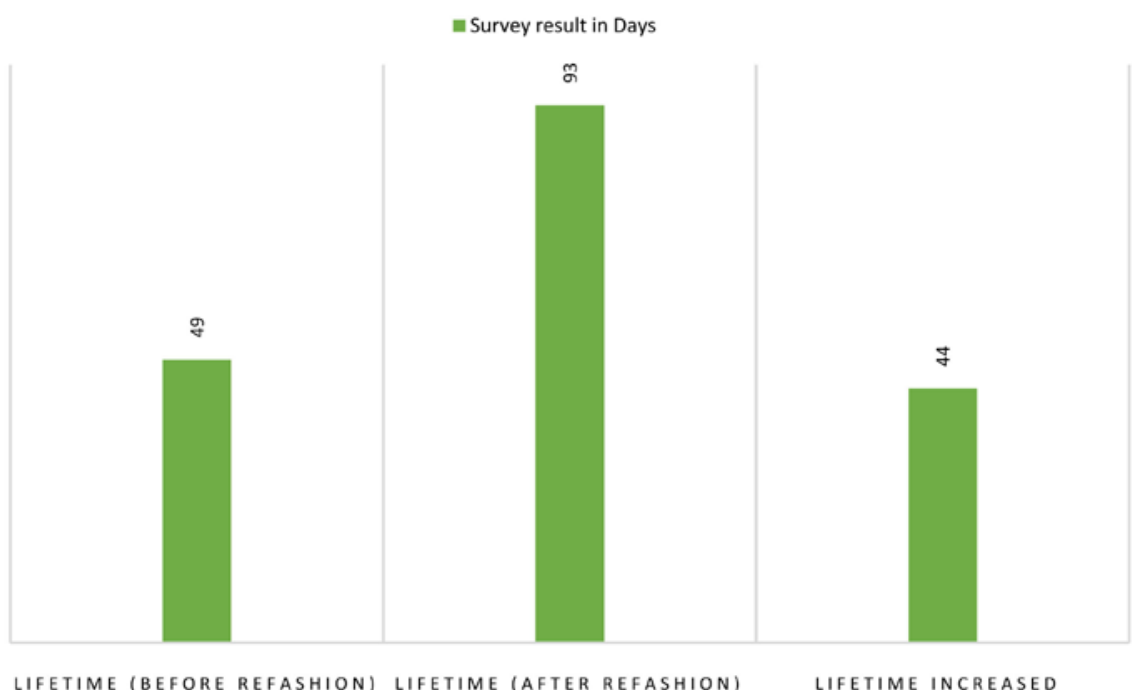

Figure 14. Lifetime (in days) of old woven shirt before refashion and after refashion. 


\section{Refashion approach 7: Laggings converted into crop-top}

The old laggings show more attraction to the people after converted into a beautiful lady's crop top by refashioning (Figure 15). It has little critical mechanism though comes with a great result. survey result over the 500 people shows the lifetime of the old woven shirt before refashion is 42 days and the value increases to 70 days after refashion. Hence it can be concluded that the lifetime of the mentioned item increases to 28 days, it can be concluded that refashion can give a more lucrative look to the garment which increases lifetime and reduces wastage (Figure 16).

\section{Refashion approach 8: Summer T-shirt converted into winter shirt}

When two old garments are combined, a great result can be made by refashioning. Here an old jacket and an old T-shirt are combined and transformed into a stylish T-shirt (Figure 17). a huge appreciation can be seen as per survey result over the 500 people the lifetime of the old t-shirt before refashion is 41 days and the value increases to 65 days after refashion which shows that lifetime of the mentioned item increases to 24 days, it can be concluded that useful lifespan of the old t-shirt increases in a great value (Figure 18).

Refashion approach 9: T-shirt converted into casual jacket

The old $\mathrm{t}$-shirt can also be transformed into a beautiful jacket by refashioning (Figure 19). As per the survey result of over 500 people, the lifetime of the old

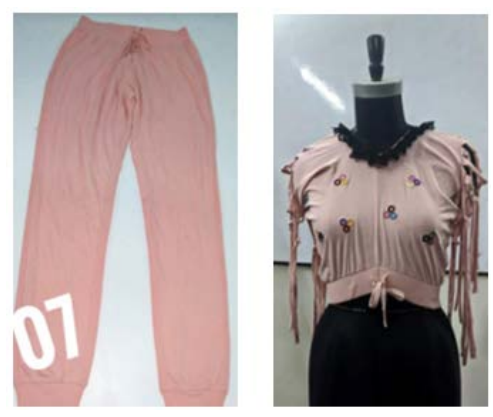

Figure 15. Legging before and after refashion.

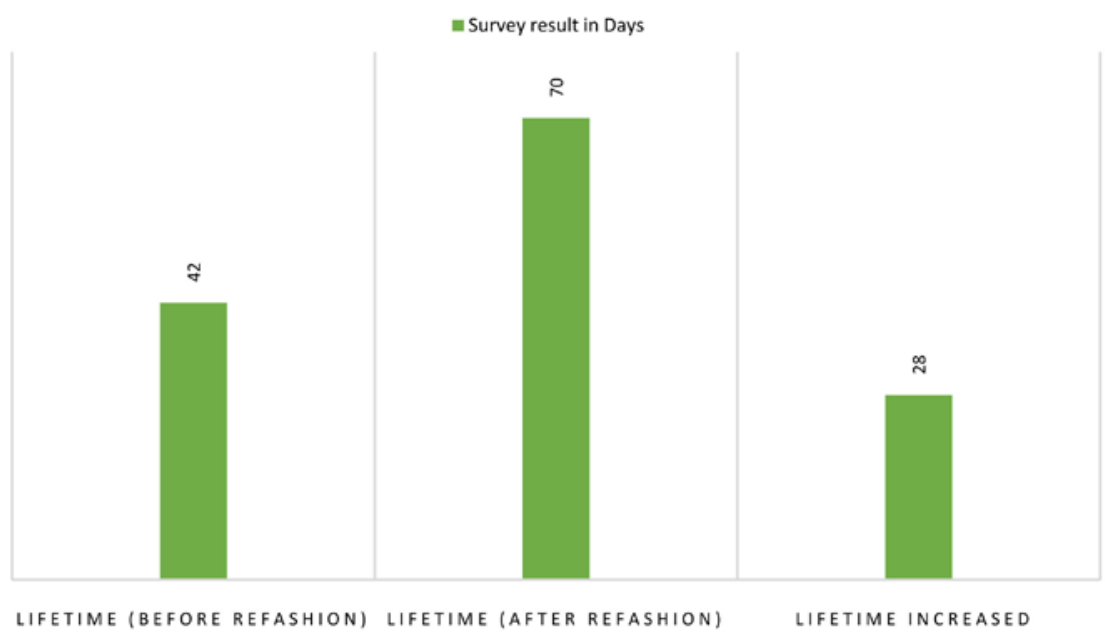

Figure 16. Lifetime (in days) of lagging before refashion and after refashion. 


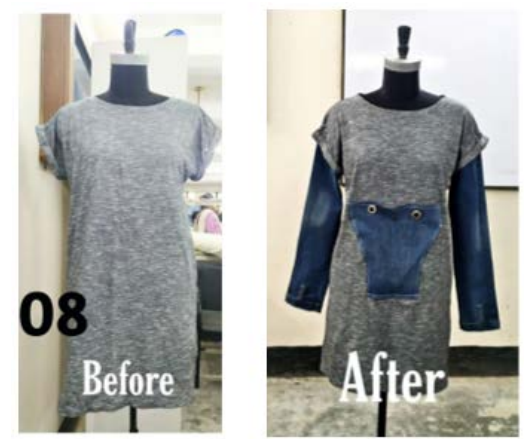

Figure 17. T-Shirt before and after refashion.

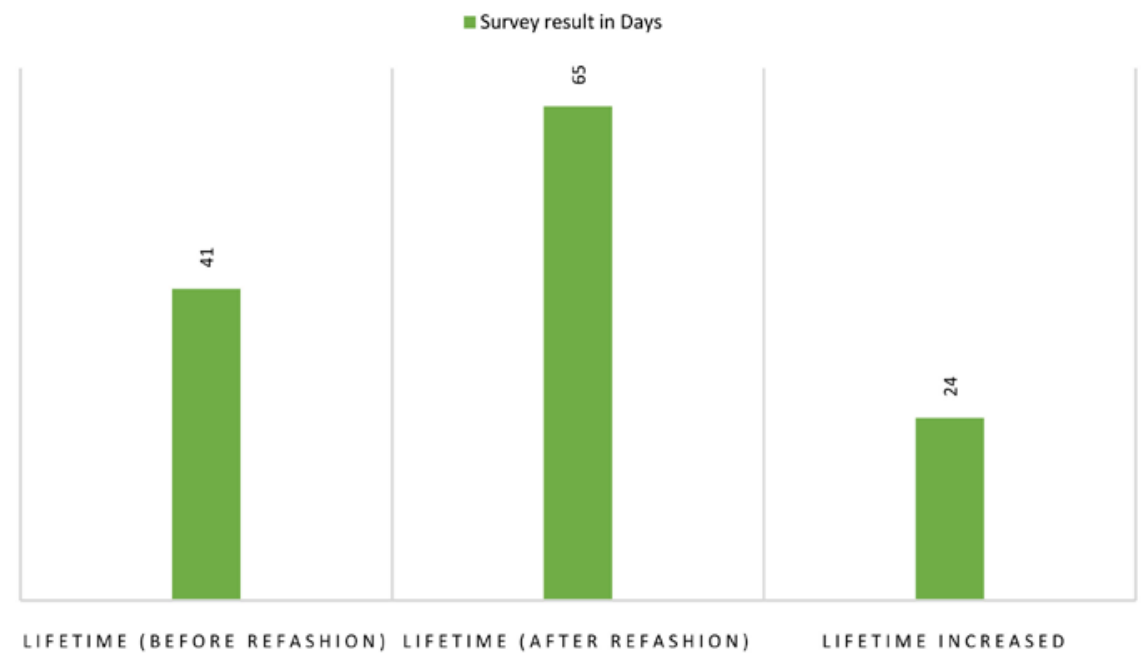

Figure 18. Lifetime (in days) of old T-shirt before refashion and after refashion.

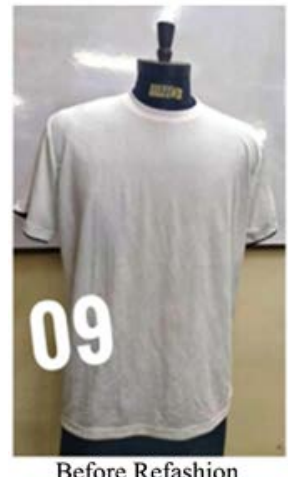

Before Refashion

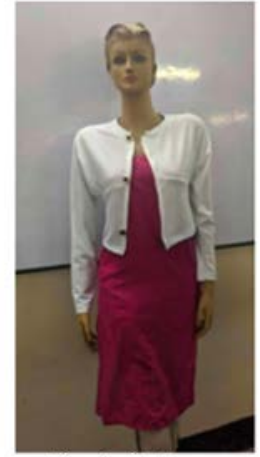

After Refashion

Figure 19. T-Shirt before and after refashion.

$\mathrm{t}$-shirt before refashion is 43 days, and the value increases to 89 days after refashion. Hence it can be concluded that the lifetime of the mentioned item increases to 46 days which is a huge appreciation of people. It was also the most lucrative refashioned item among the others (Figure 20).

Refashion approach 10: Jeans converted into detachable overall

People may not hear of converting an old denim pant into a detachable overall (Figure 21). But it also came with a great result and appreciation as per survey 
result over the 500 people the lifetime of the old jeans before refashion is 49 days and the value increases to 82 days after refashion. Hence it can be concluded that the lifetime of the mentioned item increases to 33 days, it can be concluded that useful lifespan of the old jeans increases in a great value (Figure 22).

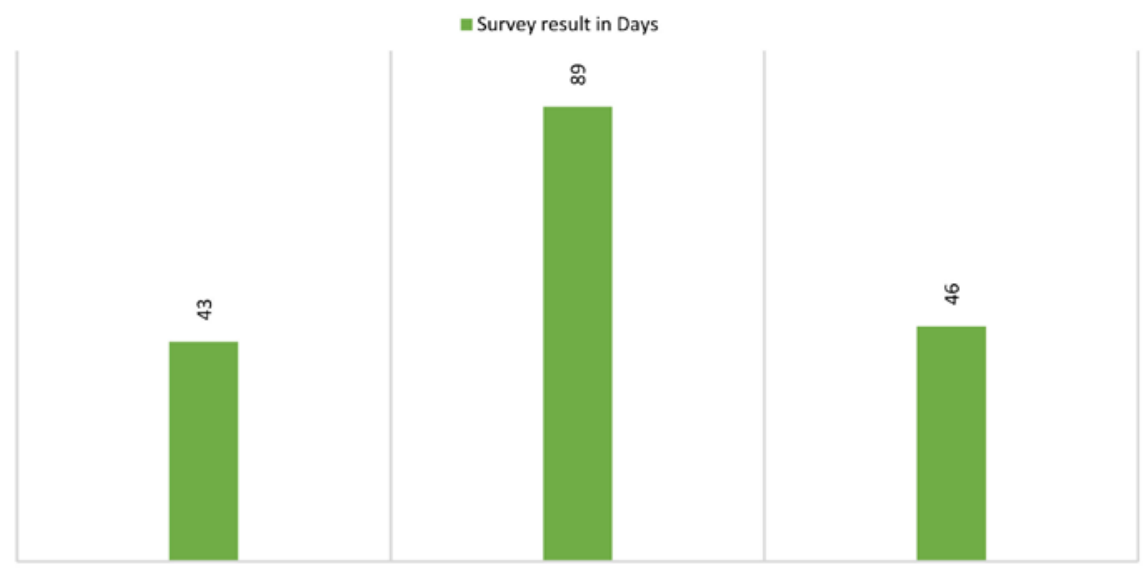

LIFETIME (BEFORE REFASHION) LIFETIME (AFTER REFASHION)

LIFETIME INCREASED

Figure 20. Lifetime (in days) of old T-shirt before refashion and after refashion.

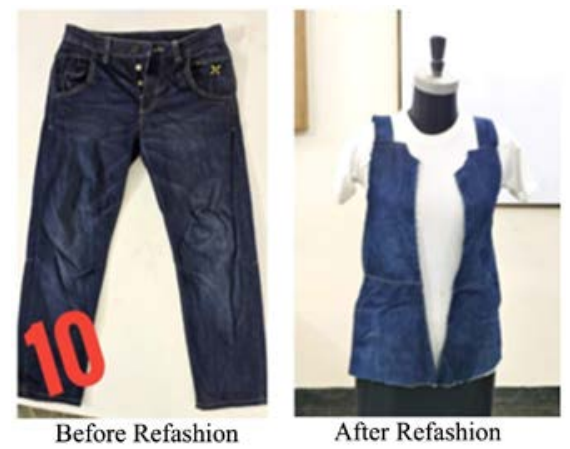

Figure 21. Jeans before and after refashion.

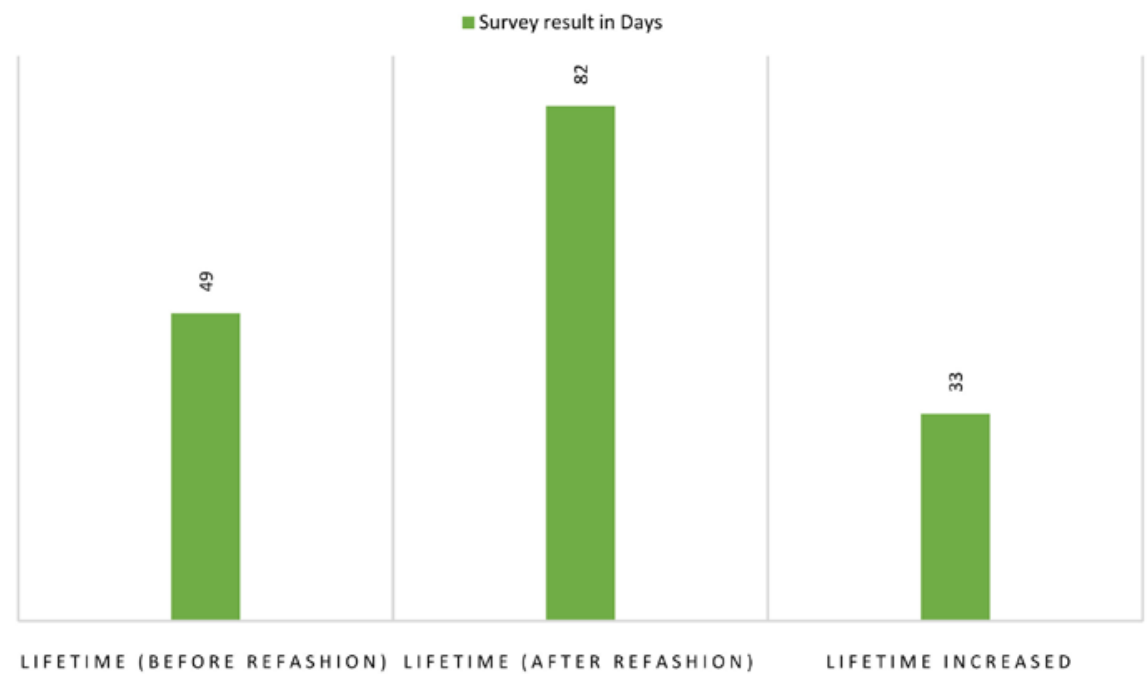

Figure 22. Lifetime (in days) of old denim jeans before refashion and after refashion. 


\section{Conclusion}

This research work mainly focuses on the refashion of different garments to increase the lifetime of the garments. Applying refashion increases the useable lifetime of different garments. The result shows that lifetime of Denim jacket, T-Shirt, Jeans, Basic shirt, Ladies T-Shirt, Ladies Shirt and leggings increases to 29 days, 29 days, 24 days, 27 days, 37 days, 44 days and 28 days respectively. Also, the lifetime of the T-Shirt converted to winter shirt and Casual jacket increases to 24 days and 46 days respectively. This result makes this research work with an eco-friendly approach. It can be concluded that the findings of this research work have an environmental, social, and economic impact.

\section{Future Scope}

- One can do further research on how the buying behavior of customers can be changed if refashion is adopted on old garments.

- One can develop a business model for mass production of refashion.

\section{Conflicts of Interest}

The authors declare no conflicts of interest regarding the publication of this paper.

\section{References}

Ahmed, T., Mia, R., \& Tanjim, M. J. (2020). An Extensive Analysis of the Health Hazards for RMG Workers in Apparel Sector of Bangladesh. Journal of Textile Engineering \& Fashion Technology (JTEFT), 6, 141-146.

Allwood, J., Laursen, S. E., Russell, S., de Rodriguez, C. M., \& Bocken, N. J. (2008). An Approach to Scenario Analysis of the Sustainability of an Industrial Sector Applied to Clothing and Textiles in the UK. Journal of Cleaner Production, 16, 1234-1246. https://doi.org/10.1016/j.jclepro.2007.06.014

Baidya, K., Ahmed, T., Mia, R., Habib-A-Rasul, S. S., Das, A., Bardhan, A., \& Saha, P. (2020). Study on Yarn Quality Variation from Spinning Position to Position in Ring Frame.

Brenot, A., Chuffart, C., Coste-Manière, I., Deroche, M., Godat, E., Lemoine, L., \& Tornaire, C. (2019). Water Footprint in Fashion and Luxury Industry. In Water in Textiles and Fashion (pp. 95-113). Amsterdam: Elsevier. https://doi.org/10.1016/B978-0-08-102633-5.00006-3

Brink, M., \& Escobin, R. J. F. (2003). Plant Resources of Southeast Asia.

Choi, T.-M. (2013). Fast Fashion Systems: Theories and Applications. Boca Raton, FL: CRC Press. https://doi.org/10.1201/b16230

Dissanayake, G., \& Sinha, P. J. (2015). An Examination of the Product Development Process for Fashion Remanufacturing. Resources, Conservation and Recycling, 104, 94-102. https://doi.org/10.1016/j.resconrec.2015.09.008

Fjerbaek, L., Christensen, K. V., \& Norddahl, B. (2009). A Review of the Current State of Biodiesel Production Using Enzymatic Transesterification. Biotechnology and Bioengineering, 102, 1298-1315. https://doi.org/10.1002/bit.22256

Follows, S. B., \& Jobber, D. (2000). Environmentally Responsible Purchase Behaviour: A 
Test of a Consumer Model. European Journal of Marketing, 34, 723-746. https://doi.org/10.1108/03090560010322009

Gwilt, A., \& Rissanen, T. (2012). Shaping Sustainable Fashion: Changing the Way We Make and Use Clothes. Abingdon-on-Thames: Routledge. https://doi.org/10.4324/9780203126172

Habib-A-Rasul, S. S., \& Saleh, M. A. (2020). Statistical Analysis of Fiber Quality to Obtain a Correlation between the Fiber and Yarn Quality. Journal of Textile Engineering \& Fashion Technology (JTEFT), 6, 236-239.

Hischier, R. J. (2018). Car vs. Packaging-A First, Simple (Environmental) Sustainability Assessment of Our Changing Shopping Behaviour. Sustainability, 10, 3061. https://doi.org/10.3390/su10093061

Hossain, L., Sarker, S. K., \& Khan, M. (2018). Evaluation of Present and Future Wastewater Impacts of Textile Dyeing Industries in Bangladesh. Environmental Development, 26, 23-33. https://doi.org/10.1016/j.envdev.2018.03.005

Klepp, I. G., Laitala, K., \& Wiedemann, S. (2020). Clothing Lifespans: What Should Be Measured and How. Sustainability, 12, 6219. https://doi.org/10.3390/su12156219

Koszewska, M. J. (2018). Circular Economy-Challenges for the Textile and Clothing Industry. Autex Research Journal, 18, 337-347. https://doi.org/10.1515/aut-2018-0023

Kozlowski, A., Bardecki, M., \& Searcy, C. (2012). Environmental Impacts in the Fashion Industry: A Life-Cycle and Stakeholder Framework. The Journal of Corporate Citizenship, 45, 17-36.

Mia, R., Selim, M., Shamim, A., Chowdhury, M., \& Sultana, S. (2019). Review on Various Types of Pollution Problem in Textile Dyeing \& Printing Industries of Bangladesh and Recommandation for Mitigation. Journal of Textile Engineering \& Fashion Technology, 5, 220-226. https://doi.org/10.15406/jteft.2019.05.00205

Mohanty, A., Misra, M. A., \& Hinrichsen, G. (2000). Biofibres, Biodegradable Polymers and Biocomposites: An Overview. Macromolecular Materials and Engineering, 276, $1-24$. https://doi.org/10.1002/(SICI)1439-2054(20000301)276:1<1::AID-MAME1>3.0.CO;2$\underline{\mathrm{W}}$

O'Cass, A. (2004). Fashion Clothing Consumption: Antecedents and Consequences of Fashion Clothing Involvement. European Journal of Marketing, 38, 14. https://doi.org/10.1108/03090560410539294

Rahman, M. M., Haque, T. M. A., Sourav, N. S., Rahman, S., Yesmin, S., Mia, R., \& Begum, K. (2020). Synthesis and Investigation of Dyeing Properties of 8-Hydroxyquinoline-Based Azo Dyes. Journal of the Iranian Chemical Society. https://doi.org/10.1007/s13738-020-02070-2

Reza, B., Soltani, A., Ruparathna, R., Sadiq, R., \& Hewage, K. (2013). Environmental and Economic Aspects of Production and Utilization of RDF as Alternative Fuel in Cement Plants: A Case Study of Metro Vancouver Waste Management. Resources, Conservation and Recycling, 81, 105-114. https://doi.org/10.1016/j.resconrec.2013.10.009

Shim, S. (1995). Environmentalism and Consumers' Clothing Disposal Patterns: An Exploratory Study. Clothing \& Textiles Research Journal, 13, 38-48. https://doi.org/10.1177/0887302X9501300105

Tue, N. M., Sudaryanto, A., Minh, T. B., Isobe, T., Takahashi, S., Viet, P. H., \& Tanabe, S. (2010). Accumulation of Polychlorinated Biphenyls and Brominated Flame Retardants in Breast Milk from Women Living in Vietnamese e-Waste Recycling Sites. Science of the Total Environment, 408, 2155-2162. https://doi.org/10.1016/j.scitotenv.2010.01.012 
Weber, S., Lynes, J., \& Young, S. (2017). Fashion Interest as a Driver for Consumer Textile Waste Management: Reuse, Recycle or Disposal. International Journal of Consumer Studies, 41, 207-215. https://doi.org/10.1111/ijcs.12328

Yeheyis, M., Hewage, K., Alam, M. S., Eskicioglu, C., \& Sadiq, R. (2013). An Overview of Construction and Demolition Waste Management in Canada: A Lifecycle Analysis Approach to Sustainability. Clean Technologies and Environmental Policy, 15, 81-91. https://doi.org/10.1007/s10098-012-0481-6

Zamani, B., Sandin, G., \& Peters, G. M. (2017). Life Cycle Assessment of Clothing Libraries: Can Collaborative Consumption Reduce the Environmental Impact of Fast Fashion? Journal of Cleaner Production, 162, 1368-1375.

https://doi.org/10.1016/j.jclepro.2017.06.128 